\title{
Ordinary Language, Conventionalism and a priori Knowledge
}

\author{
Henry JACKMAN†
}

\begin{abstract}
This paper examines popular 'conventionalist' explanations of why philosophers need not back up their claims about how 'we' use our words with empirical studies of actual usage. It argues that such explanations are incompatible with a number of currently popular and plausible assumptions about language's 'social' character. Alternate explanations of the philosopher's purported entitlement to make a priori claims about 'our' usage are then suggested. While these alternate explanations would, unlike the conventionalist ones, be compatible with the more social picture of language, they are each shown to face serious problems of their own.
\end{abstract}

In his essay "On the verification of statements about ordinary language," Benson Mates argues that the evidence philosophers typically have for their claims about how 'we' use our words (armchair introspection) is of suspect quality (Mates 1958, 124-5). This paper will examine an influential 'conventionalist' response to Mates' challenge, and argue that it is incompatible with the assumption that we share a language in any robust sense. It will then suggest a number of alternative accounts of how philosophers could be entitled to such a priori knowledge of how 'we'use our terms. Finally, it will raise some questions about the applicability of these alternative accounts to the sorts of philosophically disputed cases for which such a priori intuitions are typically brought to bear.

In response to Mates' suggestion that ordinary language philosophers should engage in the empirical study of actual usage, Stanley Cavell made three claims about statements such as "When we ask whether an action is voluntary we imply that the action is fishy" (hereafter " $S$ ") that generated considerable interest and controversy. Such "categorical declaratives" were, according to Cavell, (1) necessarily true, (2) knowable a priori, and (3) neither analytic nor synthetic (Cavell 1958, 13). Many philosophers simply

${ }^{\dagger}$ York University, Department of Philosophy, S428 Ross Building, 4700 Keele Street, M3J 1P3 Toronto, Canada.

Dialectica Vol. 55, Nº 4 (2001), pp. 315-325 
rejected Cavell's characterization of statements like $S,{ }^{1}$ but others had similar intuitions about such statements and sought to give an account of them. In doing so, many arrived at "conventionalist" accounts of statements like $S$ which were in many respects like Poincaré's account of how the axioms of geometry 'define' the meaning of geometric primitives. Viewed from outside the conceptual framework, statements such as $S$ were taken to collectively define the framework itself. Viewed from inside the framework, they were taken to express claims that are necessarily true of the phenomena understood within the framework. ${ }^{2}$

Such a conventionalist explanation of the philosopher's knowledge of what 'we' would say is presented explicitly by Zeno Vendler. Vendler contrasts "external" statements such as "Is $X$ voluntary?' implies that $X$ is fishy" with "internal" statements such as "When we ask whether an action is voluntary we imply that the action is fishy." "While the internal and external statements will, as Cavell puts it, be "true together and false together" (Cavell 1958, 13), there are important "logical differences" between them (Vendler 1967, 21). In particular, these logical differences reflect the difference between "the empirical task of finding the rules constitutive of the conceptual framework, and the investigation into the a priori correlations that obtain within that framework" (Cavell 1958, 13). External statements are synthetic in a way in which internal ones are not. As Vendler puts it:

While it is possible to envision different constraints on the use of the phoneme sequence know or cause, it is impossible to grasp what knowing something false or causing a horse would be like. In much the same way, while it is possible to imagine different rules governing the moves of the piece called "Bishop", it is impossible to imagine a checkmate of a lone King achieved by a King and a Bishop alone. The first half of these two sentences envisions a somewhat different language or game from what we actually have, while the second half invites us to think something impossible in the language or game we do in fact have. (Vendler 1967,23.)

It is not surprising that Vendler draws an analogy with chess, since the rules governing games lend themselves extremely well to the type of axiomatic status that the conventionalist hopes to find for our linguistic characterizations.

\footnotetext{
${ }^{1}$ For instance, Fodor \& Katz clearly oppose Cavell's characterization of S on all three counts (Fodor \& Katz 1963).

${ }^{2}$ For a useful discussion of Poincaré's position, see Coffa 1991, esp. ch. 7. It has recently been argued that such appeals to implicit definitions can be separated from conventionalism itself (Boghossian 1997). Nevertheless, the argument of this paper should be unaffected by such considerations, since it turns on the problems associated with the conventionalist's appeal to such implicit definitions, not the 'non-factualism' associated with their position.

${ }^{3}$ Vendler 1967, 21. Here Cavell's " $S$ " and "T" (Cavell 1958) are used as instances of Vendler's internal and external statements respectively. Vendler (perhaps uncharitably) sees his own account as what we are left with if we "pare away the trimmings of mysticism" from Cavell's (Vendler 1967, 12). That Cavell might not be happy with such a conventionalist interpretation of his position is suggested in Cavell 1962.
} 
Game analogies also appear in John Searle's Speech Acts as part of a response to Mates'challenge. Searle points out that he knows that in baseball, after hitting the ball fair, the batter runs in the direction of first base rather than, say, the left field grandstand. He argues that this knowledge is neither confined to particular instances of base-running behavior, nor something that he ever looked up in a book. Indeed, Searle insists that, if there were a rulebook that said anything contrary to his statement of the rule, the book would be mistaken, or at least be describing a different game. Searle's knowledge is "based on knowing how to play baseball, which is inter alia having internalized a set of rules." Searle goes on to suggest that his knowledge of linguistic characterizations like $S$ is of a similar kind. As he puts it, "the answer to the philosophers'question of 'what would you say if ...?' is not a prediction about future verbal behavior, but a hypothetical statement of intention within a system of rules, where mastery of the rules dictates the answers." 4 Searle makes the connection between being a native speaker of a language and mastering the conditions for the correct application of its terms very clear when he claims that "The 'justification'I have for ... my linguistic characterizations is simply that I am a native speaker of a certain dialect of English and consequently have mastered the rules of that dialect." 5 Searle thus explains the philosopher's ability to know how we would use our words in terms of the members of our linguistic community having mastered the same practice and being aware of this shared mastery. ${ }^{6}$

There is, however, a serious problem with this sort of conventionalist account of our knowledge of how 'we'use our terms. This becomes clear when we return to Searle's baseball analogy. Searle is committed to saying that those

${ }^{4}$ Searle 1969, 14. Searle mentions Mates explicitly as the target of these reflections (Searle 1969, 5).

${ }^{5}$ Searle 1969 , p. 13. (Italics mine). Hare makes a similar claim when he compares ordinary language philosophers to people who have previously 'mastered'a dance and are now trying to remember how it goes (Hare 1960). See also Cavell 1958, 5.

${ }^{6}$ The most influential account of such mutually known shared mastery is found in David Lewis's Convention, and the connection between his theory and the philosopher's knowledge of what 'we'would say is not lost on Lewis.

Once we have acknowledged that someone is a native speaker of our language, we have already granted that he is a party to our conventions. Therefore he knows what those conventions prescribe; he knows "what we would say" in the sense in question. If we turn around and ask him to produce evidence for what he says about what we would say, we challenge his status as a native speaker and a party to the conventions. We do not challenge some further status he might claim as an authority on the conventions as well as a party to them. He has evidence - perfectly ordinary evidence. But if we ask him to show it, we question his membership in the linguistic community to which he purports to belong. It makes no sense both to demand evidence for what he says about the conventions and to take for granted that he is party to those conventions. (Lewis 1969, 63.) Lewis's views will not be discussed further here, but they are dealt with in considerable detail in Jackman 1998. 
who played 'baseball'in accordance with a different set of rules would not be playing baseball incorrectly, but rather would be playing a game other than baseball. In much the same way, conventionalists must characterize those who fail to share their linguistic characterizations as speaking a language other than their own. ${ }^{7}$ For instance, Searle admits that other people, in what he takes to be his dialect group, might use their words other than the way he does, but he insists that in such a case it would not follow that his linguistic characterizations were false statistical generalizations from insufficient empirical data. Indeed, Searle claims that his linguistic characterizations are not empirical generalizations at all. As he puts it:

That my idiolect matches a given dialect group is indeed an empirical hypothesis (for which I have a lifetime of 'evidence'), but the truth that in my idiolect "oculist" means eye doctor is not refuted by evidence concerning the behavior of others (though, if I find that my rules do not match those of others, I shall alter my rules to conform). (Searle 1969, 13.)

At this point the conventionalist's claim to have an account of our a priori knowledge of what 'we'would say seems to collapse. One knows a priori how one's own language is used, but it becomes "an empirical hypothesis" that others speak this language as well. I may know, a priori, how I use my terms, but whether there is any 'we'that does is an empirical matter which I can only know a posteriori.

The conventionalist presupposes that we each have complete mastery of our own language, and that when we bring our usage into line with others, we are changing our language, not learning something about the language that we had been speaking all along. Consequently, in addition to loosing grip on the usage of the 'we', the conventionalist's response is individualistic in a sense that has recently come to strike many as implausible. At the time of the original Mates/Cavell debate, it was still commonly presupposed that each speaker had, on his or her own, command of the conditions of application of the terms in his or her language. It has, however, become increasingly clear that, if we share a language, then we often lack such complete mastery over how all of our terms are used. Content ascriptions consistent with the assumption that we share a language suggest that a speaker's discriminatory capacities often underdetermine or even misidentify what one is talking about.

A typical example of underdetermination is Hilary Putnam's use of "beech" and "elm" (Putnam 1975, 226). While Putnam cannot distinguish beeches from elms, we still take the extensions of "beech" and "elm" in his idiolect, like ours, to be the sets of all beech and elm trees respectively. There is, as Putnam puts it, a "division of linguistic labor," and we often rely upon other

${ }^{7}$ Conventionalists would also suggest that those who allow their 'pawns'to move both backward and forward are not playing chess incorrectly, but rather playing a game other than chess. (See, for instance, Haugeland 1998.) 
speakers' knowledge to help determine the referents of our own terms. The best known case of misidentification is Tyler Burge's discussion of Bert and his belief that he has arthritis in his thigh (Burge 1979). In this example, Bert tells his doctor that he has arthritis in his thigh, the doctor informs him that arthritis only affects the joints, and Bert gives up his belief. In spite of the fact that Bert's beliefs may be uniquely true of something else (a set of ailments affecting the joints and thighs which we can call "tharthritis"), Bert is taken to have here corrected a mistaken belief about arthritis. Burge further argues that, had Bert's community used the term "arthritis" to pick out tharthritis, Bert would have had a set of true beliefs about tharthritis (and no arthritis beliefs at all). What Bert is talking and thinking about seems, in part, determined by how the word "arthritis" is used in his community.

The ascriptions following from the assumption that we share a language with our fellows suggest, then, that we are occasionally unable to completely or even accurately specify how our own words are properly used. One upshot of Putnam's and Burge's work is thus that the claim that we have mastered the conditions of application of all our terms is incompatible with the natural assumption that our language is shared. If one wants there to be a language that 'we' speak at all, the requirement that we have fully mastered our language must be given up. It thus seems that, once the division of linguistic labor is incorporated into our picture of language, we cannot claim to know a pri ori how all the terms in our own language are used. On the conventionalist conception of language, then, one presupposes language mastery, but there is no assurance that there is any 'we'that speaks the language. On the more contemporary accounts, one is assured that one shares a language with others, but this assurance comes with a corresponding uncertainty about one's mastery of one's own language. It seems, then, that neither picture of language provides one with a priori entitlement to claim both that one knows how one's terms are properly used, and that other people speak one's language.

Nevertheless, current theories that take languages to be more 'robustly' shared may still allow one to make a priori claims about how 'we' use at least some of our terms. ${ }^{8}$ One need only give an account of how one could know what 'we'would say that replaces the picture of shared languages in which all speakers fully master the same practice with one in which speakers rely upon each other's varying degrees of expertise. Doing so involves recognizing that, with respect to many parts of the language, those with a high degree of mas-

${ }^{8}$ Though the use of "a priori" here will be in a somewhat extended sense. The sorts of approaches discussed will all require that our judgments about what 'we'would say be based on some empirical evidence, it is just that the evidence in question will not be about how other speakers use the words that the claims are being made about. 
tery are able to correct others, and others will defer to their usage. Those with a high degree of mastery in a certain area are thus entitled to produce "categorical declaratives" for the terms relating to that area. A doctor, for example, can produce categorical declaratives such as "Such a thing we would call a fracture rather than a break." By contrast, I would not (and have no inclination to) produce such declaratives about fractures. Expert status entitles one to produce categorical declaratives precisely because people defer to expert usage. A doctor can talk about what 'we' would call a fracture because, if his and the public's usage differ, the public can be expected to bring themselves into line. Expert status can thus give one a type of authority to specify what 'we' would say. ${ }^{9}$ The question remains, then, whether the ordinary language philosopher could claim such authoritative status for his own usage.

One might try to give an explanation of the philosopher's knowledge of what 'we'would say on this 'expert'model. On such an account, philosophers could make authoritative claims about how 'we'use the technical terms relating to their own profession. Philosophers know what 'we'would call an "ontological argument" or a "Kantian", since they are the "experts' with respect to this portion of the vocabulary. Unfortunately, ordinary language philosophers were interested in making claims about how 'we' use words such as "voluntary", "deliberate", "properly" or "knows", not about such technical vocabulary. The 'expert'explanation of how the philosopher knows what 'we'would say thus fails to cover the sorts of cases that needed to be justified.

One might also try to explain the philosopher's authority to issue categorical declaratives in terms of the 'prestige' of his or her person or dialect. I may defer to the usage of another not because I take his or her to be an expert on a given topic, but rather because I take his or her English to be more 'correct' or 'proper' than mine. In light of this, it is worth remembering that the ordinary-language philosophers'method could be described as involving a sort of collective a priori. It was, after all, quite common for them to discuss the usage of various words with each other (to say nothing of consulting the O.E.D.), so they could be fairly confident that their pronouncements were characteristic of how the words were used by, say, Oxford dons. ${ }^{10}$ Consequently, if Oxford usage were authoritative for English speakers in general, then they could claim that knowing how words were used in their group was enough to know how

\footnotetext{
${ }^{9}$ Being an expert is just one way of being 'authoritative' about some aspect of communal usage. Such authoritative status could also come, for instance, from holding an official position relating to some part of the vocabulary. The magistrates'decisions on whether a certain range of action counts as "negligent" etc. is perhaps the paradigmatic case of someone deciding ( a priori) how 'we'use our terms.

${ }^{10}$ See, for instance, the discussion of Austin's "play group” in Grice 1986 and Strawson 1998.
} 
'we'used such words. Such a methodology would involve (in spite of Cavell's protestations to the contrary) the philosopher's "scorning the speech of his charwoman out of solicitude for that of his nanny" (Cavell 1962, 57). Nevertheless, if the rest of the community were willing to defer to the nanny's usage, such a methodology might well be appropriate. Of course, the claim that people are willing to defer to the nanny's (or Oxford's) usage is by no means uncontroversial. Indeed, while there is undoubtedly a tendency to defer to various types of 'prestige' usage, it is often overestimated, especially by members of the prestige groups. (Even the OED can be ignored with impunity in many quarters.) Consequently, this proposed explanation, in addition to being unhelpful to those philosophers practicing outside of Oxford, would seem to rest on a number of dubious sociolinguistic assumptions.

Another, more modest, approach would be to claim that when the ordinary language philosopher speaks of "we", he means not "we speakers of English", but rather something like "we Oxford-educated Englishmen." Their claims would thus not be about how ordinary people (not Oxford philosophers) use their terms, bur rather about how philosophers ordinarily (non-philosophically) use their terms. Of course, Ryle claims to be concerned with how "ordinary folk ... generally apply the words 'voluntary' and 'involuntary"' (Ryle $1949,69)$, so it is tempting to see him as making a statement about how people, in general, use these words. Nevertheless, there is some reason to think that Ryle is implicitly engaged in something like this more modest project. Cavell's baker (who insists that he uses "automatically" and "inadvertently" interchangeably) (Cavell 1958, 34-6) is noticeably absent from Ryle's list of 'ordinary folk' which includes only "magistrates, parents and teachers" (Ryle 1949, 69). If one picks the right parents and magistrates (Oxford graduates), and the right teachers (Oxford dons), Oxford dons would be fairly representative of Ryle's 'ordinary folk.' This more modest explanation would, however, leave it unclear why the ordinary language philosopher's claims should be of any interest to anyone other than his colleagues. ${ }^{11}$ Still, on such an account, the ordinary language philosopher might seem able to make a justified claim about this more limited 'we', and then at least hope that it would resonate with other speakers as well. ${ }^{12}$

A final type of explanation would involve the ordinary language philosopher as claiming to be authoritative about how 'we'use a particular word not in virtue of his or her official position, but rather in virtue of his or her dialec-

\footnotetext{
${ }^{11}$ And for a suggestion that their claims have only such limited interest, see Feyerabend 1975,154

12 This would seem consistent with Cavell's claim that "The Philosophical appeal to what we say, and the search for our criteria on the basis of which we say what we would say, are claims to community." (Cavell 1979, 20)
} 
tical abilities. Some speakers may (through their ability to produce distinctions, precisifications, counterexamples and equivalencies) be able to persuade other speakers about how various terms in their language should be used..$^{13}$ Such speakers could, like officially recognized authorities, make categorical declaratives that hold good for the entire community. If others were not initially inclined to share their characterizations, they could be persuaded that they were mistaken in doing so. Of course, this profile seems to fit many philosophers, most notably Austin, particularly well. ${ }^{14}$ If, say, Austin's conceptual and analytical skills are such that he could consistently persuade others about the linguistic questions he considers, then he may be entitled to make categorical declaratives about what 'we' would call "deliberate" or "voluntary". These declaratives could be true even if many of us did not initially use the words in question in precisely the way Austin claimed that 'we' did. The ordinary language philosopher could thus claim to produce 'reflective' agreement on various categorical declaratives even if he or she were unable to secure 'immediate' agreement from his interlocutors.

This particular strategy, however, seems to run counter to a methodological orientation that seemed quite dear to ordinary language philosophers. On such an account, claims about what 'we' would say turn out to be normative rather than descriptive claims. They are claims about how 'ordinary' people should, rather than $d o$, use their words. Consequently, almost any claim about proper usage would have the potential to be justified with this model. The skeptic could, after all, claim that "we' would not claim to "know" anything beyond what we immediately experience. People do not actually talk this way, but the skeptic could claim to secure (through a familiar battery of arguments) 'reflective' agreement from his interlocutors that they should, in fact, use the term this way. This final line of defense, then, would allow the philosopher to make extremely reversionary claims about how our ordinary terms should be used, and this seems to be precisely the sort of procedure that the ordinary language philosophers saw themselves as opposing.

There are thus four sorts of justification compatible with the more social picture of language that one could claim for one's claims about what 'we' would say. First, one could claim a particular authority qua philosopher for those parts of the vocabulary that philosophers are considered to be the experts. Secondly, if one were a member of a prestigious dialect group such as, say, Oxford Dons, one could claim that speakers of other dialects would defer to one's usage. Thirdly, one could claim to be speaking only for the

${ }^{13}$ Burge describes such speakers and their importance in Burge 1986.
${ }^{14}$ See, for instance, the description of Austin in Grice 1986. 
dialect group whose usage one has, in fact, canvassed. Finally, one could claim to be the most persuasive discussants about how certain parts of the vocabulary are best used. It is perhaps not surprising that paradigmatic ordinary language philosophers such as Austin and Ryle could claim to be authoritative in all four of these senses.

Nevertheless, in addition to the problems with the four suggestions mentioned above, there are other reasons that philosophers should be wary of relying entirely on their own intuitions about language. In particular, each of these explanations presupposes a degree of uniformity at least among philosophers' intuitions about how 'we' use our words. There are, however, reasons to be suspicious of this assumption. Cavell compares the ordinary language philosopher to the "linguistic theorist using examples from his native speech" (Cavell $1958,4-5)$, and the problems this methodology poses for linguists may be relevant to philosophers. Syntacticians' intuitions about grammaticality do not always converge with each other, and when they diverge, they do so in disturbingly predictable ways. In particular, syntacticians' intuitions about grammaticality tend to be largely shaped by the syntactic theories they favor, so that syntacticians committed to competing theories will often have competing intuitions about which sentences 'we'would find grammatical. ${ }^{15}$ In such cases, empirical work on actual usage can be both relevant and surprising, in spite of the fact that introspective syntacticians are generally right about which sentences we typically would find grammatical. The problem with appealing to our own intuitions about grammaticality to settle syntactic disputes is that the sentences relevant to the disputes are often precisely those about which our intuitions are most shaped by our theories.

There is some danger that the philosopher's appeal to 'what we would say' will be subject to this same problem. Different philosophers have different intuitions about, for instance, what counts as "voluntary," and many of them insist that their intuitions on the use of the term correspond to those of ordinary speakers. For instance, while Cavell seems to take $S$ to be in accord with what 'we' would say, it strikes many as false, perhaps even as 'obviously' false. Any philosopher's intuitions about whether or not 'we' would refer to a man's movements while sleeping as "deliberate" are probably sound. Nevertheless, when he gets to more complex cases where he is supposed to decide whether 'we'would refer to a particular action as intentional, deliberate, both, or neither, there are some reasons to think that the philosopher's intuitions may be shaped by his theoretical commitments. ${ }^{16}$ One can see instances of this in

15 For a discussion of this see Thomason 1991.

16 And Mates is quite clear that it is only such problem cases he is concerned with. (Mates 1958, 315.) 
Russell's and Strawson's respective claims about whether or not what 'we' would say is in accord with Russell's account of descriptions. ${ }^{17}$ These 'biases' may not simply be removable by 'cool reflection.' Speaker's innocent of syntactic theory are often unable to make any firm grammaticality judgments about disputed syntactic cases, and unaided by some sort of theory, we simply may not have any firm intuitions about what to say in philosophically disputed cases either. On the accounts suggested above, philosophers can only make an authoritative claims about how 'we' use our words if there is a consensus within the authoritative community, and this seems to be lacking in many of the cases where we make such appeals. If there is no such consensus, then there will be no unified 'expert', 'prestige' or 'persuasive' community that the rest of the population could be understood as deferring to. And if there are no such unified communities, then there is no 'we' that the individual philosopher can assume to speak for.

In conclusion, the popular 'conventionalist' response to Mates' assertion that philosophers typically have poor evidence for their claims about how 'we' use our words is incompatible with the assumption that we share a language in any robust sense. Nevertheless, philosophers could still be entitled to make a priori claims about how 'we' use certain terms if they were 'authoritative' in their community with respect to the use of those terms. However, if and when philosophers have such authority is far from clear. Furthermore, a philosopher could only presume to such authoritative status if there was a consensus among the philosophical community. Unfortunately, in those philosophically disputed cases for which such a priori intuitions are frequently brought to bear, there may be no consensus among philosophers about how the terms should be used, and thus no facts about what 'we' would say to appeal to.*

${ }^{17}$ See Strawson 1950 and Russell 1957. For a more contemporary conflict, consider how Davidson and Burge each claim that our 'everyday'ascriptions are in line with their respective opinions about whether or not what we mean by our words is socially determined (Burge 1979, Davidson 1987).

* I'd like to thank Robert Brandom, Joe Camp, Dan Everett, John McDowell, Ram Neta, Jonathan Weinberg, and participants at the 2000 Mid-South Philosophy conference for comments on earlier versions of this essay. 


\section{REFERENCES}

Boghossian, P. 1997, “Analyticity”, in Hale and Wright (eds.) A Companion to the Philosophy of Language, Malden: Blackwell, 1997.

BuRge, T. 1979, "Individualism and the Mental", in French, Uehling \& Wettstein. Midwest Studies in Philosophy IV: Studies in Metaphysics, Minneapolis: University of Minnesota Press (73-121).

Burge, T. 1986, "Intellectual norms and the Foundations of Mind", The Journal of Philosophy, Dec 1986.

CAVell, S. 1958, "Must we mean what we say?" Inquiry, vol. 1. (Page references to version in Cavell 1969.)

CAVELL, S. 1962, "The availability of Wittgenstein's later philosophy", The Philosophical Review, LXXI. (Page references to version in Cavell 1969.)

CAvell, S. 1969, Must we mean what we say? New York: Cambridge University Press.

CAVell, S. 1979, The Claim of Reason, New York: Oxford University Press.

CofFA, A. 1991, The Semantic Tradition from Kant to Carnap, New York: Cambridge University Press.

DAVIDSON, D.1987, "Knowing One's Own Mind”, Proceedings and Addresses of the American Philosophical Association.

Feyerabend, P.K. 1975, Against Method, Thetford: Thetford Press Limited.

FODOR \& KATZ, 1963, "The availability of what we say", The Philosophical Review, LXXII. (Reprinted in Lyas 1971.)

GricE, P. 1986, "Reply to Richards", in Grandy and Warner (eds.) Philosophical Grounds of Rationality, New York: Oxford University Press.

HARE, R.M. 1960, "Philosophical Discoveries", Mind, LXIX. (Reprinted in Lyas 1971.)

Haugeland, J.1998, "Truth and Rule-Following”, in his Having Thought, Cambridge: Harvard University Press, 1998.

JACKMAN, H. 1998, "Convention and Language", Synthese, 117 (3) 1998:295-312.

LEwIS, D. 1969, Convention, Cambridge: Harvard UP.

LYAS, C. (ed.) 1971, Philosophy and Linguistics, London: Macmillan.

MATES, B. 1958, "On the verification of statements about ordinary language", Inquiry, vol. 1. (Page references to version in Lyas 1971.)

PutNAM, H. 1975, "The Meaning of 'Meaning'", reprinted in his Mind Language and Reality, New York: Cambridge University Press.

Russell, B. 1957, "Mr. Strawson on Referring”, reprinted in his My Philosophical Develop ment, London: George Allen \& Unwin, 1959.

RYLE, G. 1949, The Concept of Mind, London: William Brendon and Son

SEARLE, J. 1969, Speech Acts, New York: Cambridge University Press.

Strawson, P.F. 1950, “On Referring”, in his Logico-Linguistic Papers, London: Methuen, 1971.

Strawson,P.F. 1998, "Intellectual Autobiography”, in Hahn, (ed) The Philosophy of P.F. Straw son, Chicago: Open Court, 1998.

Thomason, S. 1991, "Thought experiments in linguistics", in Horowitz and Massey (eds.) Thought experiments in science and philosophy, Savage, Md.: Rowman \& Littlefield

VendLer, Z. 1967, Linguistics in Philosophy, Ithaca: Cornell University Press. 